\title{
Incremento de lodo de ETA em barreiras impermeabilizantes de aterro sanitário
}

\section{Increment of sludge from water treatment plant in waterproofing barriers of sanitary landfill}

Data de entrada: 19/01/2015

- Data de aprovação: $17 / 02 / 2016$

Flávia Gonçalves, Caio Henrique Ubukata de Souza, Fernando Shigueu Tahira, Fernando Fernandes, Raquel Souza Teixeira

DOI: $10.4322 /$ dae.2016.018

\section{Resumo}

A disposição inadequada de resíduos sólidos no solo é prejudicial ao ambiente, sobretudo, pelo potencial poluidor do lixiviado. Buscando minimizar este impacto ambiental, barreiras impermeabilizantes são projetadas para impedir a percolação dos líquidos gerados. A codisposição do lodo de estação de tratamento de água (ETA), misturado ao solo, em camadas de impermeabilização de fundo, cobertura diária e cobertura final de aterros sanitários, mostra-se interessante. $\mathrm{O}$ objetivo deste trabalho foi avaliar características físico-químicas de misturas de lodo de ETA, após desidratação em leito de drenagem, a solos argilosos e arenosos para aplicação nestas barreiras. Os traços solo : lodo utilizados foram $1: 0,5$ e $1: 1$ para o solo argiloso e $1: 0,25$ para o solo arenoso. Para os traços estudados foram realizados os ensaios de compactação e permeabilidade. A granulometria do lodo seco foi classificada como pedregulhosa. Observou-se que todos os materiais apresentaram coeficiente de permeabilidade $\left(\mathrm{k}\right.$ ) na faixa de $10^{-10}-10^{-9} \mathrm{~m} \cdot \mathrm{s}^{-1}$, enquadrando-se como materiais de baixa permeabilidade, indicados para uso em obras de aterro sanitário.

Palavras-chave: Mistura lodo ETA - Solo; Compactação; Permeabilidade.

\section{Abstract}

The inappropriate disposal of solid waste on soil is harmful to the environment, mainly for the pollution potential of the leachate. In order to minimise this environmental impact, waterproofing barriers are designed to stop percolation of generated fluids. The co-disposal of sludge from Water Treatment Plant (WTP), mixed to the soil, as layers for bottom waterproofing, daily covering and final covering of sanitary landfills proves to be interesting. The aim of the study was to assess physicochemical characteristics of WTP's sludge, after dehydration at drying bed, mixed to clayey and sandy soils for application on these barriers. Traces soil : sludge utilised were 1:0,5 and $1: 1$ for the clayey soil and 1:0,25 for the sandy soil. Compaction and permeability tests were conducted for the traces in study. Grain size of dried sludge was classified as gravelly. It was observed that all materials presented permeability coefficient ( $\mathrm{k}$ ) at the range of $10^{-10}-10^{-9} \mathrm{~m} \cdot \mathrm{s}^{-1}$, fitting in as low permeability materials, indicated for using at sanitary landfill works.

Keywords: Mixture WTP’s sludge - Soil; Compaction; Permeability.

Flávia Gonçalves - Bacharel em Engenharia Ambiental, pela Universidade Tecnológica Federal do Paraná (2013). Especialista em Engenharia de Segurança do Trabalho (2015) e Mestre em Engenharia de Edificações e Saneamento (2016), ambos pela Universidade Estadual de Londrina. Doutoranda em Engenharia Civil pela Universidade Estadual de Londrina e professora da Universidade Técnológica Federal do Paraná e Universidade Norte do Paraná."

Caio Henrique Ubukata de Souza - Graduando do $5^{\circ}$ ano de engenharia civil pela Universidade Estadual de Londrina.

Fernando Shigueu Tahira - Graduado em engenharia civil pela Universidade Estadual de Londrina (2016). Atualmente é aluno do curso de pós-graduação em Lean Manufacturing na Pontifícia Universidade Católica do Paraná e trabalha na área de processos de engenharia na empresa Plaenge Empreendimentos.

Fernando Fernandes - Graduado em engenharia civil pela UNICAMP (1980) e doutor em engenharia pelo Institut National Polytéchnique de Toulouse (1989). Atualmente é Professor Associado no Centro de Tecnologia e Urbanismo da Universidade Estadual de Londrina (UEL)

Raquel Souza Teixeira - Possui graduação em Engenharia Civil pela Universidade Federal de Ouro Preto (1992), mestrado em Geotecnia pela Escola de Engenharia de São Carlos (EESC) / Universidade de São Paulo (1996) e doutorado em Engenharia Civil pela Universidade Federal de Santa Catarina (2008) com período de bolsa sanduíche no Institut National de la Recherche Agronomique - INRA de Versailles/França. Atualmente é professora adjunto da Universidade Estadual de Londrina.

" Endereço para correspondência: flavia_goncalves.fgahotmail.com 


\section{Introdução}

O problema da gestão de resíduos sólidos é preocupante não apenas pelo volume gerado atualmente, mas também pela possibilidade de contaminação do solo e das águas da área de disposição e de seu entorno. A disposição inadequada de resíduos sólidos no solo é prejudicial ao ambiente, sobretudo, pelo potencial poluidor do lixiviado, líquido proveniente da decomposição anaeróbia dos resíduos acrescido de águas pluviais (LANGE et al., 2009). Buscando minimizar este impacto ambiental, barreiras impermeabilizantes são projetadas para impedir a percolação dos líquidos gerados. A impermeabilização da base e das laterais do aterro pode ser feita por meio de geomembranas sintéticas e/ou com camadas de solo impermeável (BOSCOV, 2008).

A partir da proibição da prática de despejo do lodo de estação de tratamento de água (ETA) em corpos hídricos, por meio da Resolução CONAMA n³57/2005, alternativas, preferencialmente contemplando usos benéficos, passaram a ser avaliadas. Dentre os destinos encontrados estão: a disposição em aterros sanitários; o lançamento em estação de tratamento de esgoto; recupera- ção de áreas degradadas; aplicação na agricultura; incremento ao solo ou a misturas, por exemplo, solo-cimento; aditivos na argila para a fabricação de tijolos e cerâmica vermelha; entre outros (PEREIRA, 2011; KATAYAMA, 2012).

O lodo de ETA é constituído prioritariamente por frações inorgânicas - compostas por argila, silte, areia fina - mas também pode apresentar material húmico e microrganismos, além de produtos provenientes do processo de coagulação. É um resíduo pertencente à Classe II A - não perigoso e não inerte (ABNT, 2004). Deste modo, sua codisposição com emprego em camadas de impermeabilização de fundo, cobertura diária e cobertura final de aterros sanitários, mostra-se como uma possibilidade interessante.

No entanto, para que sua aplicação seja fundamentada, os critérios geotécnicos de impermeabilização de aterro sanitário devem ser obedecidos, tais como distribuição de frações granulométricas adequadas e baixa permeabilidade. A Tabela 1, retirada de Boscov (2008), apresenta uma compilação dos valores mínimos de alguns parâmetros para solos a serem atendidos segundo diferentes fontes.

Tabela 1 - Requisitos mínimos para solo de impermeabilização de aterros sanitários

\begin{tabular}{|l|l|l|l|}
\hline \multicolumn{1}{|c|}{ Característica } & \multicolumn{1}{|c|}{ OMAFRA (2003) } & \multicolumn{1}{c|}{ CPA (1989) } & $\geq 30$ \\
\hline $\mathrm{LL}(\%)^{(1)}$ & $30 \leq \mathrm{LL} \leq 60$ & $\geq 15$ \\
\hline $\mathrm{IP}(\%)^{(2)}$ & $11 \leq \mathrm{IP} \leq 30$ & $\geq 10$ & $\geq 30$ \\
\hline Finos $\phi \leq 0,075 \mathrm{~mm}(\%)$ & $\geq 50$ & $\geq 20$ & \\
\hline Fração Argila $\phi \leq 0,002 \mathrm{~mm}(\%)$ & $\geq 20$ & & \\
\hline Fração Areia $0,075 \mathrm{~mm}<\phi \leq 4,8 \mathrm{~mm}(\%)$ & $\leq 45$ & \\
\hline Fração Pedregulho $\phi>4,8 \mathrm{~mm}(\%)$ & $\leq 50$ & $\leq 10$ & \\
\hline $\mathrm{k}\left(\mathrm{m} / \mathrm{s}^{\left({ }^{(3)}\right.}\right.$ & $\leq 10^{-9}$ & $\leq 10^{-9}$ & \\
\hline
\end{tabular}

Fonte: adaptado de Boscov (2008).

Nota: ${ }^{(1)}$ Limite de Liquidez; ${ }^{(2)}$ Índice de Plasticidade; ${ }^{(3)}$ Coeficiente de permeabilidade.

Uma vez respeitados tais parâmetros geotécnicos, a codisposição não implica na redução da vida útil do aterro sanitário, principal problema mencionado quanto à disposição do lodo nestes locais, de- vido ao grande volume que ocupa. Além disso, o uso do lodo, ou sua co-codisposição, possibilita a redução de áreas de empréstimos de terra para a operacionalização do confinamento de resíduos. 
O objetivo deste artigo é avaliar as características físico-químicas das misturas de lodo de ETA com solos argilosos e arenosos para aplicação em barreiras impermeabilizantes (impermeabilização de fundo, cobertura diária e cobertura final) de aterro sanitário.

\section{METODOLOGIA}

\section{a) Solos}

O solo de caráter argiloso utilizado neste estudo foi coletado a $2 \mathrm{~m}$ de profundidade no Campo Experimental de Engenharia Geotécnica (CEEG), localizado no campus da Universidade Estadual de Londrina (UEL), na cidade de Londrina/PR, enquanto que o solo arenoso foi coletado em um talude às margens da rodovia PR 376 - km 37, próximo à cidade de Madaguaçu/PR.

A caracterização física do solo argiloso foi realizada por Hauly (2010), Teixeira et al. (2013) e Rodriguez et al. (2013). Quanto ao solo arenoso, a caracterização foi feita por Silva et al. (2009) e Beraldo et al. (2011). Para tanto foram levados em consideração os parâmetros: 1) Análise granulométrica - realizada por peneiramento e sedimentação, seguindo o procedimento descrito na norma NBR 7181/1984; 2) Limites de consistência - liquidez e plasticidade - feitos com material peneirado em \#40 (0,46mm), seguindo as normas NBR 6459/1984 e NBR 7180/1984; e 3) Massa específica dos sólidos - realizada com o material peneirado em \#10 (2mm). Para a determinação da curva granulométrica, a massa específica dos sólidos utilizada é a obtida com material passante na peneira \#10 (2,0mm) e segundo os procedimentos da norma NBR 6508/1984.
Para a caracterização química dos solos foram realizadas as análises de: 1) pH (em $\mathrm{KCl}$ ); 2) carbono (método Walkley Black); 3) matéria orgânica - MO (obtida em razão do C); e 4) capacidade de troca catiônica - CTC. Todas as análises químicas dos solos foram realizadas pelo Laboratório de Solos do Instituto Agronômico do Paraná - IAPAR, de Londrina e pelo Laboratório de Química do Solo da Universidade Estadual de Londrina.

b) Lodo

O lodo utilizado no estudo foi proveniente da ETA Cafezal, localizada na cidade de Londrina - PR. A estação trabalha com tratamento de ciclo completo e utiliza como coagulante em seu processo o Cloreto Férrico Hexahidratado $\left(\mathrm{FeCl}_{3} \cdot 6 \mathrm{H}_{2} \mathrm{O}\right)$. Sabe-se que em ETAs de ciclo completo a maior quantidade de lodo (em termos mássicos) é gerada nos decantadores. Na ETA Cafezal existem cinco decantadores: dois com capacidade de $900 \mathrm{~m}^{3}$ que acumulam aproximadamente $240 \mathrm{~m}^{3}$ de lodo cada, enquanto que os outros três, com capacidade de $1500 \mathrm{~m}^{3}$, têm acumulação aproximada de $375 \mathrm{~m}^{3}$ de lodo em cada um (SILVEIRA, 2012).

Por se tratar de um material tixotrópico, ou seja, apresenta-se na forma de gel, com valor de umidade gravimétrica - relação de massa de água por massa de partículas sólidas - que ultrapassava 900\% (TEIXEIRA et al., 2013), foi necessário realizar a secagem em leitos para melhor trabalhá-lo. Os leitos de drenagem (2,5 $\mathrm{m}$ de comprimento e $1,0 \mathrm{~m}$ de largura - Figura 1) continham como material de enchimento uma camada de 0,20 m de brita $n^{\circ} 3$, sobreposta por mantas geotêxtil, conforme especificações de Silva et al. (2008). 


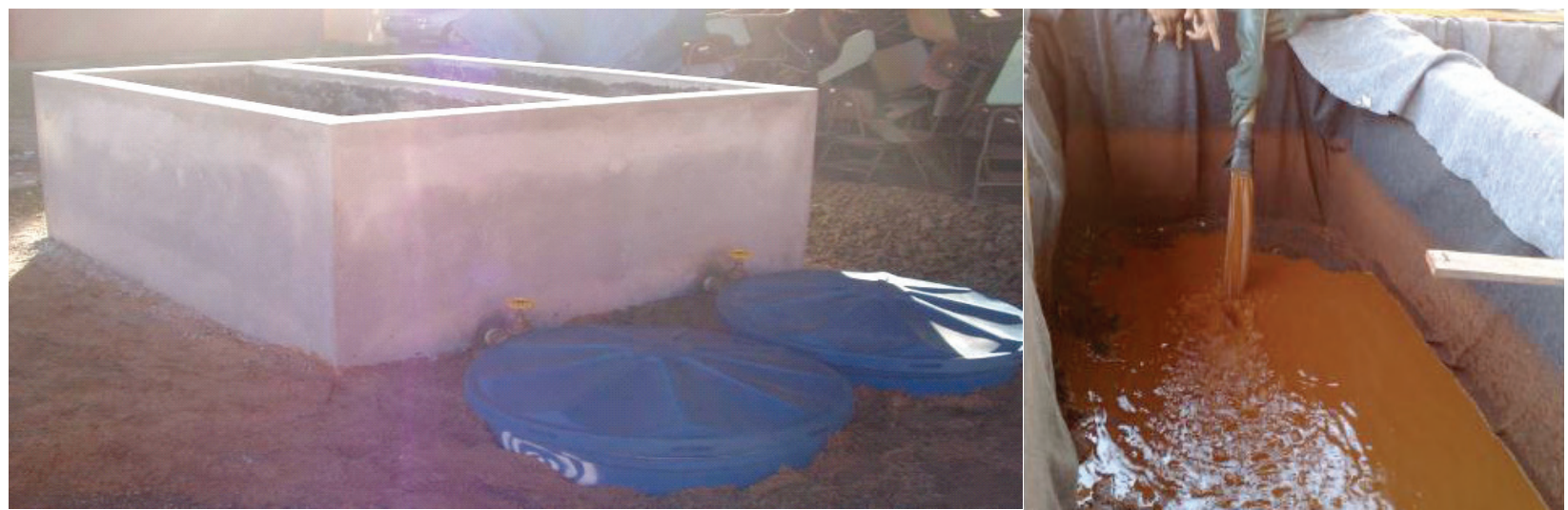

Figura 1 - Leito de drenagem utilizado no desaguamento do lodo de ETA

Fonte: Silva et al., 2008

Inicialmente foi colocado um volume de aproximadamente $1,25 \mathrm{~m}^{3}$ de lodo (camada de 0,5 m de altura) em cada reservatório, cuja umidade foi determinada segundo a NBR $6457 / 1986$, periodicamente (5, 8, 15, 30 e 45 dias), a fim de acompanhar sua variação. A amostra de lodo seco foi obtida quando a umidade atingiu valor abaixo de $15 \%$ (OLIVEIRA JUNIOR et al., 2010), o que foi evidenciado após o trigésimo dia. O material caracterizava-se neste momento como granular de tamanho pedregulho (BERALDO et al., 2011). A sequência de fotos da Figura 2 mostra a contração do lodo, durante o período de perda de umidade até aproximadamente $15 \%$. Pode-se observar desde a formação de agregados até a transformação do lodo em um material granular.

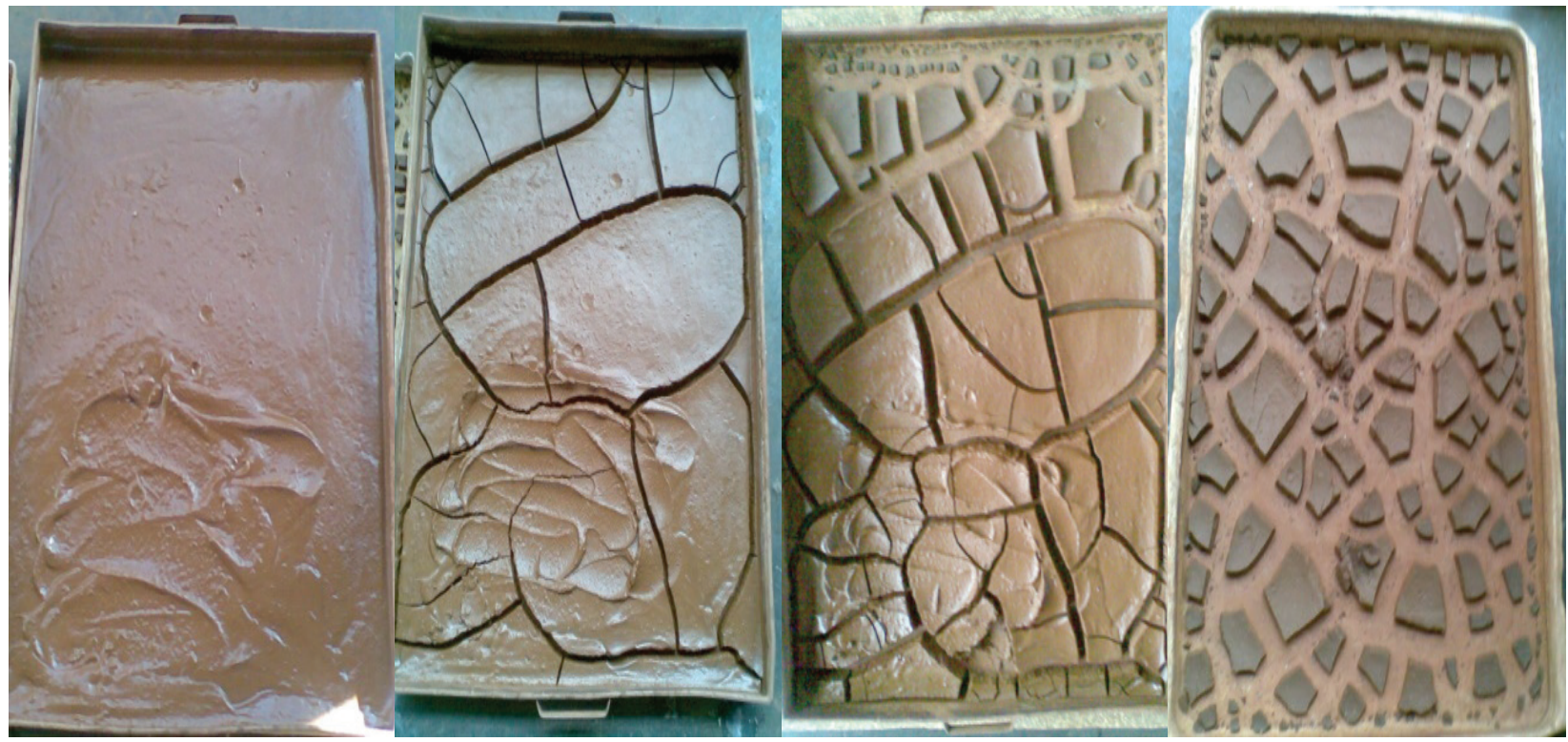

Figura 2 - Transformação do lodo de ETA do estado líquido para sólido Fonte: Teixeira et al., 2013 
Para avaliar a possibilidade da codisposição do lodo de ETA em barreiras impermeabilizantes de aterros sanitários, seja na impermeabilização de fundo ou coberturas diária e final, o material deve apresentar características físico-químicas que sejam semelhantes às do solo utilizado para a finalidade. Deste modo, Teixeira et al. (2013) analisaram o lodo conforme os mesmos parâmetros físico-químicos mencionados para a análise do solo (análise granulométrica, limites de consistência, massa específica dos sólidos, $\mathrm{pH}$ em $\mathrm{KCl}$, carbono, MO e CTC).

\section{c) Mistura solo-lodo}

As misturas analisadas neste estudo estão apresentadas na Tabela 2 com os respectivos traços, em massa.

Tabela 2 - Traço das misturas Solo-Lodo

\begin{tabular}{|l|l|l|}
\hline \multicolumn{1}{|c|}{ Tipo de solo } & \multicolumn{1}{|c|}{ Argiloso } & \multicolumn{1}{c|}{ Arenoso } \\
\hline \multirow{2}{*}{ Proporção $^{(1)}$} & $1: 0,5$ & $1: 0,25$ \\
\hline & $1: 1$ & \\
\hline
\end{tabular}

(1) Relação Solo-Lodo, em massa.

Inicialmente os traços para a mistura solo argiloso e lodo foram escolhidos por representarem aplicações práticas em campo. Além disso, considerou-se que a combinação entre o lodo não destorroado, somente após desidratação em leito de drenagem, e o solo argiloso tivesse bom empacotamento, visto que há predomínio de partículas grossas no lodo e de partículas finas no solo, causando certo grau de equilíbrio na distribuição dos grãos.

Para o solo arenoso foram seguidos os mesmos princípios, porém, como este já se tratava de um material com maior granulometria natural, optou-se por uma menor proporção de lodo não destorroado agregada, novamente, objetivando um possível equilíbrio na distribuição de grãos no sistema. d) Ensaios de Compactação e Permeabilidade

Para ambos os solos e também para os traços solo-lodo testados, foram realizados ensaios de compactação em cilindro Proctor com Energia Normal e reuso de solo e número mínimo de cinco corpos de prova para a obtenção da curva de compactação (NBR 7182/1986). A compactação foi realizada por meio de um soquete de $2,5 \mathrm{~kg}$ em queda livre a $30 \mathrm{~cm}$ de altura, utilizando um cilindro de volume de aproximadamente $1000 \mathrm{~cm}^{3}$, aplicando-se 26 golpes em 3 camadas, sendo a primeira e a segunda camadas escarificadas após a aplicação dos golpes. Depois de compactados, os corpos de prova foram extrudados, e com as sobras de material, os teores de umidade foram verificados. Com as curvas de compactação foram obtidas as umidades ótimas ( $\omega_{\text {ótima }}$ ) e massas específicas secas máximas $\left(\rho_{\text {dMáxima }}\right)$ para os solos e para as misturas.

Os ensaios de permeabilidade foram então realizados em permeâmetro de carga variável (NBR 14545/2000), pelo método $B$, em amostras dos materiais (solo e misturas solo-lodo) compactados com umidade e massa específica secas próximas a $\omega_{\text {ótima }}$ e $\rho_{\text {dMáxima }}$. Todos os ensaios de laboratório foram realizados em via seca com grau de compactação mínimo definido em $95 \%$ e desvio máximo do teor de umidade de $\pm 1 \%$

\section{RESULTADOS E DISCUSSÕES}

a) Caracterização dos materiais

A Tabela 3 resume as características físico-químicas dos dois tipos de solo e do lodo de ETA. As curvas granulométricas dos materiais estão apresentadas na Figura 3. 
Tabela 3 - Características físico-químicas dos solos e do lodo de ETA utilizados no estudo

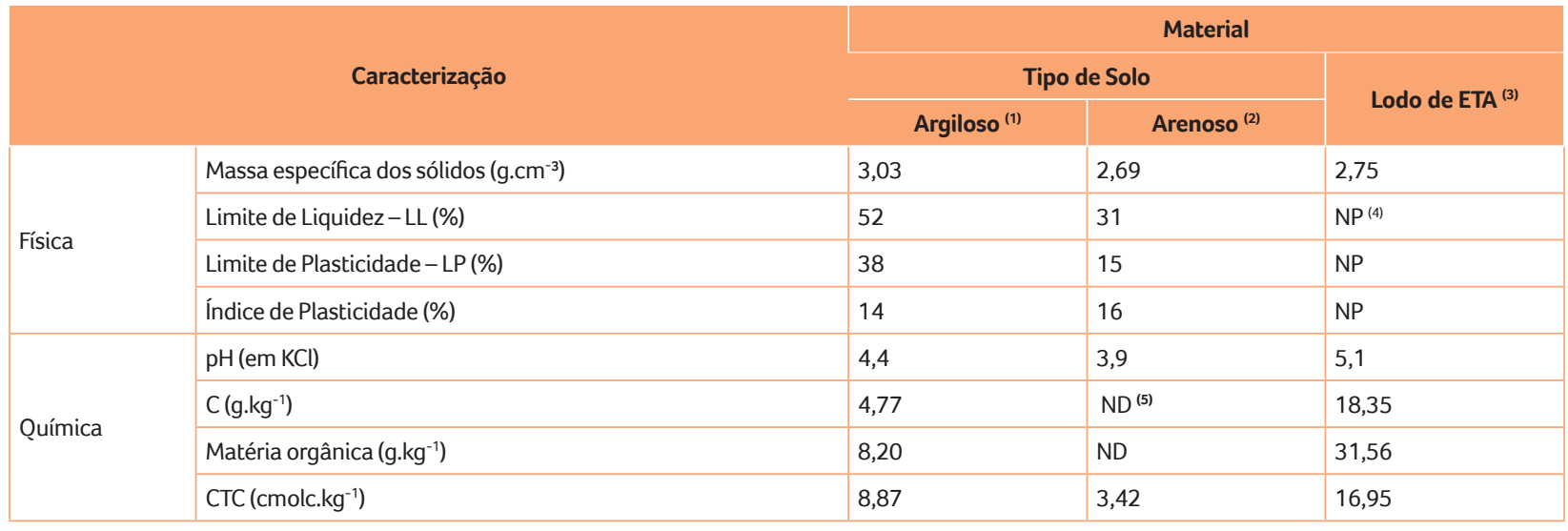

Notas: ${ }^{(1)}$ Solo de Londrina/PR; ${ }^{(2)}$ Solo de Mandaguaçu/PR; ${ }^{(3)}$ Lodo seco não destorroado; ${ }^{(4)}$ Não Plástico; ${ }^{(5)}$ Não Detectável.

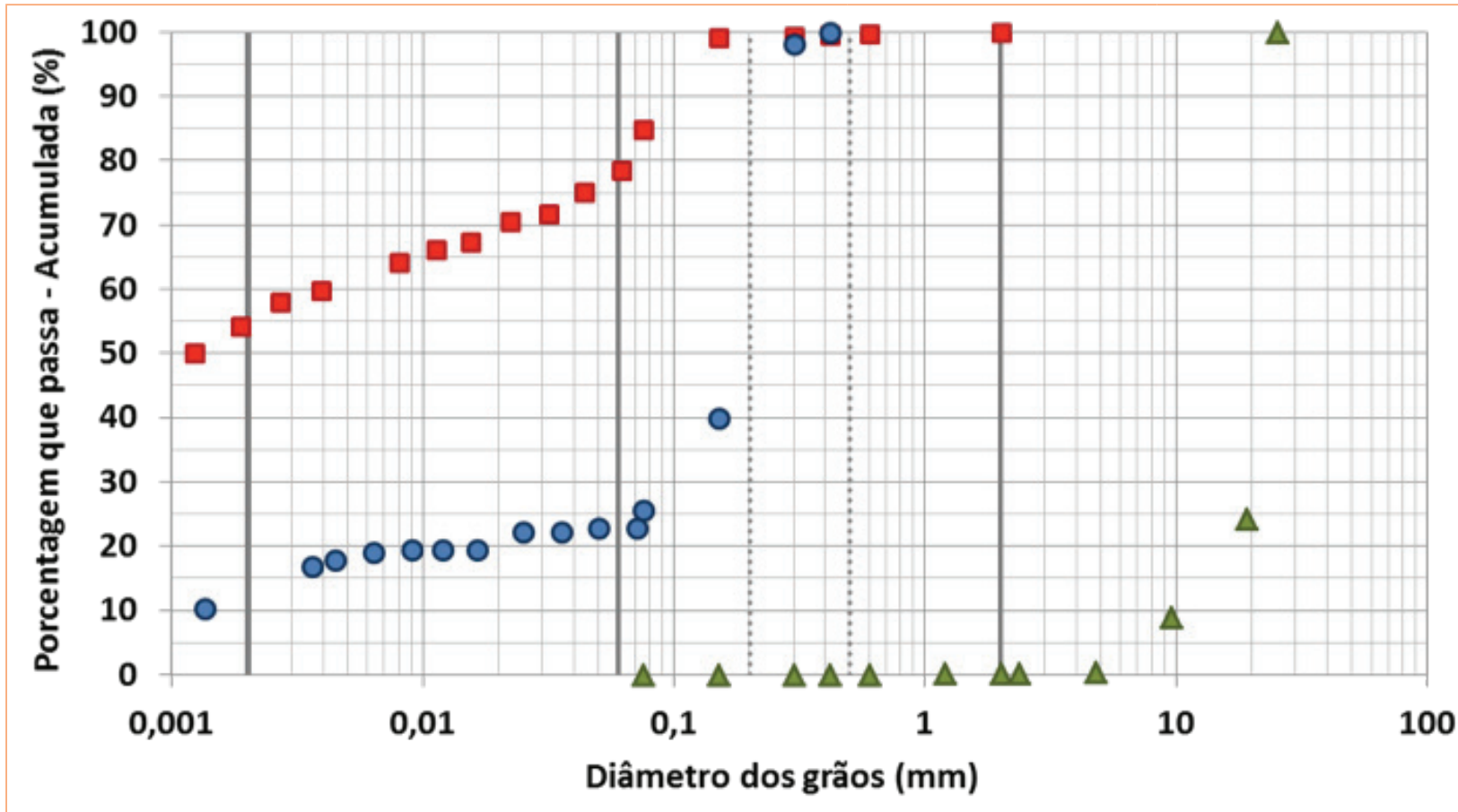

\begin{tabular}{|c|c|c|c|}
\hline \multirow{2}{*}{ Característica } & \multicolumn{2}{|c|}{ Tipo de Solo } & \multirow{2}{*}{ Lodo de ETA $^{(3)}$} \\
\hline & Argiloso ${ }^{(1)}$ & Arenoso ${ }^{(2)}$ & \\
\hline Argila (\%) & 55,50 & 13,00 & 0 \\
\hline Silte (\%) & 23,50 & 10,00 & 0 \\
\hline Areia Fina (\%) & 20,73 & 41,00 & 0,50 \\
\hline Areia Média (\%) & 0,27 & 36,00 & 2,00 \\
\hline Areia Grossa (\%) & 0 & 0 & 2,50 \\
\hline Pedregulho (\%) & 0 & 0 & 95,00 \\
\hline Classificação textural & argila siltosa & areia fina a média argilosa & pedregulho arenoso \\
\hline
\end{tabular}

Figura 3 - Curva granulométrica, percentuais e classificação textural dos materiais estudados Notas: ${ }^{(1)}$ Solo de Londrina/PR; (2) Solo de Mandaguaçu/PR; (3) Lodo seco não destorroado. 
É possível observar que a massa específica dos sólidos $\left(\rho_{\mathrm{s}}\right)$ dos dois solos apresentou valores condizentes com o que é descrito pela literatura (PAIVA NETO et al., 1951). Para o solo argiloso, o valor elevado observado $\left(\rho_{\mathrm{s}}=3,03 \mathrm{~g} \cdot \mathrm{cm}^{-3}\right)$ pode ser explicado pela significativa presença de óxidos de ferro, constituinte bastante denso que acaba por imprimir tal característica ao solo (HAULY, 2010). Já quanto ao solo arenoso, o valor $\left(\rho_{\mathrm{s}}=2,69 \mathrm{~g} \cdot \mathrm{cm}^{-3}\right)$ justifica-se pela composição ser, prioritariamente, de partículas de quartzo.

Os valores referentes aos limites de consistência para os dois tipos de solo (argiloso e arenoso) também se apresentaram como esperado, uma vez que se assemelham aos valores típicos de LL e LP citados por Belincanta e Gutierrez (2010) para solos argilosos e arenosos provenientes do sul do país. Franceschet et al. (2005) também estudaram diferentes tipos de solos utilizados para a impermeabilização da camada de base e de cobertura de aterros sanitários na região Sul, e os resultados mostram valores que corroboram com os encontrados neste trabalho. Já o lodo de ETA seco apresentou-se como material não plástico (NP), fato este justificado pela baixíssima proporção de finos, os quais respondem por apenas $0,2 \%$ de material passante na peneira $0,075 \mathrm{~mm}$ (TEIXEIRA et al., 2013). Considerando sua possibilidade de aplicação em aterros sanitários, os dois tipos de solos apresentaram os parâmetros LL e IP condizentes com o requisito mínimo preditos por Boscov (2008) - Tabela 1.

O solo argiloso deste estudo apresentou mais de $55 \%$ de partículas de tamanho argila, podendo ser classificado como argila siltosa. Rocha et al. (1991) classificou o solo desta região como sendo Latossolo vermelho-escuro laterítico. Dentre as características peculiares deste tipo de solo, tem-se seu caráter fortemente ácido e baixa CTC, ambas condições observadas nos resultados do presente estudo - $\mathrm{pH}$ de 4,4 e CTC de $8,87 \mathrm{cmol}_{\mathrm{c}}$. $\mathrm{kg}^{-1}$ (PIERANGELI et al., 2001). 0 teor de carbono orgânico e o valor aludido da matéria orgânica estão em consonância com valores esperados para solos coletados na profundidade de dois metros ou mais (TEIXEIRA et al., 2013).

O solo arenoso do presente estudo, apresentando $41 \%$ de areia fina, de um total de $77 \%$ de areia, foi classificado como areia fina a média argilosa. Este elevado teor de partículas do tamanho areia possibilitaria a inferência de que se trata de um solo com baixa capacidade de retenção de íons presentes na solução que percola, característica esta confirmada pela baixa CTC observada. No entanto, ao ser compactado, as características de atenuação de contaminantes podem ser interessantes sob o ponto de vista da impermeabilização de aterros. Hamada et al. (2004) ao trabaIharem com solos arenosos que ocorrem na região de Bauru/SP (areia fina pouco argilosa vermelha) também constataram baixa CTC e, mesmo assim, seus estudos apontaram que o solo apresentou capacidade de atenuação, especialmente quando compactado em graus acima de $85 \%$ do Proctor Normal. Não foi detectada presença de matéria orgânica no solo arenoso, provavelmente devido à localização do local de coleta do solo - parte inferior de um talude, longe da camada superior onde conhecidamente há maior concentração de materiais orgânicos.

O lodo de ETA apresentou valor de carbono orgânico e matéria orgânica consideravelmente maior do que o próprio solo argiloso. Tal ocorrência, de certa forma, era esperada, visto que no material há a concentração dos elementos encontrados no solo e, eventualmente, algas e bactérias que, junto à água, entram no processo de tratamento. Apesar disso, o teor de matéria orgânica do lodo $\left(31,56 \mathrm{~g} \mathrm{~kg}^{-1}\right)$ é inferior a teores encontrados em resíduos de aterros sanitários que, na média nacional, compreendem cerca de $50-55 \mathrm{~g} . \mathrm{kg}^{-1}$ (IPEA, 2012). Desta forma, o uso da mistura solo-lodo aparentemente não acarretaria prejuízo ambiental. A CTC no lodo é cerca de duas vezes maior que 
a do solo argiloso e mais de cinco vezes maior que a do solo arenoso, o que contribui para a retenção de metais, sendo um fator benéfico para o sistema do aterro sanitário (TEIXEIRA et al., 2013).

b) Curva de Compactação e Coeficiente de Permeabilidade

As curvas de compactação obtidas nos ensaios em laboratório estão representadas na Figura 4.

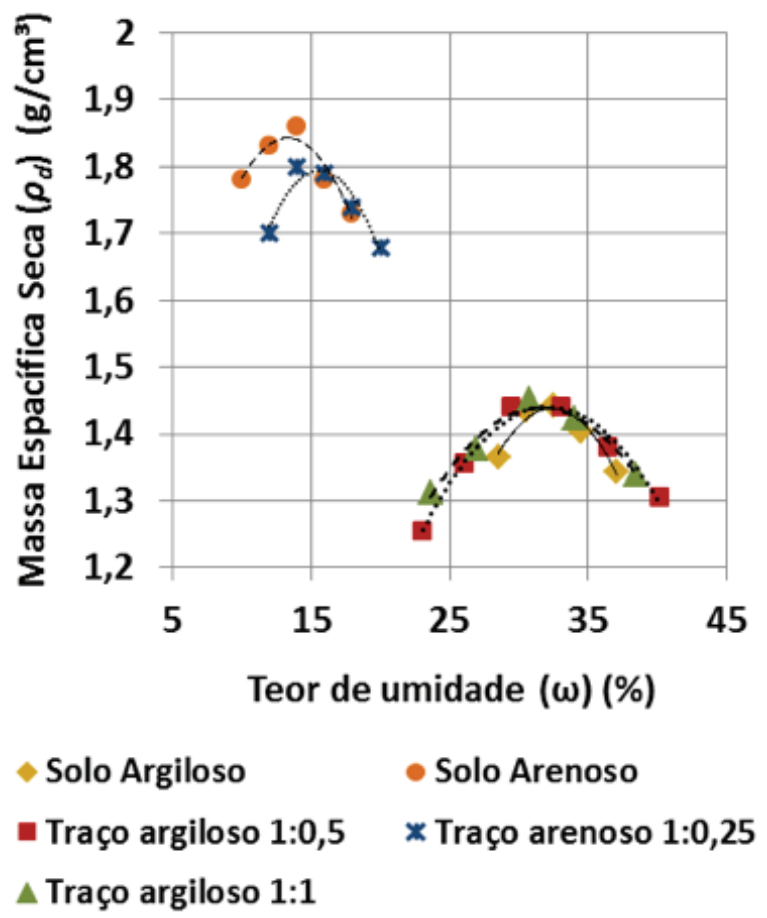

Figura 4 - Curvas de compactação dos solos e das misturas

A partir das curvas de compactação foi possível determinar os valores de $\omega_{\text {ótima }}$ e $\gamma_{\text {dMáxima }}$ para os solos e para as misturas, os quais estão apresentados na Tabela 4. Tabela 4 - Valores de $\omega_{\text {ótima }}$ e $\gamma_{\text {dMáxima }}$ dos
solos e das misturas

\begin{tabular}{|l|l|l|}
\multicolumn{1}{|c|}{ Tipo de solo } & \multicolumn{1}{|c|}{$\omega_{\text {Ótima }} \mathbf{( \% )}$} & $\rho_{\text {dMáxima }}\left(\mathbf{g} / \mathbf{c m}^{3}\right)$ \\
\hline Solo Argiloso & 32,4 & 1,43 \\
\hline Traço argiloso 1:0,5 & 32,8 & 1,44 \\
\hline Traço argiloso 1:1 & 31,8 & 1,45 \\
\hline Solo Arenoso & 14,0 & 1,86 \\
\hline Traço Arenoso 1:0,25 & 14,5 & 1,80 \\
\hline
\end{tabular}

Os resultados mostram que $\omega_{\text {ótima }}$ e $\gamma_{\text {dMáxima }}$ para o solo argiloso e para as misturas contendo este tipo de solo mostraram-se muito próximas. A mesma constatação pode ser feita para o solo arenoso e sua mistura, mas com uma ressalva - com uma maior umidade, a mistura apresentou menor massa específica seca.

Santos (2008) afirma que, comparativamente, os solos com predomínio de argila apresentam teor de umidade ótima mais elevado, conduzindo a valores mais reduzidos de massas específicas secas. Já os solos mais grosseiros têm o teor de umidade ótima mais reduzido, atingindo valores mais elevados de massa específica seca, conforme foi observado.

A permeabilidade é a propriedade do solo que avalia a facilidade de percolação de água através dos vazios do solo. Como foram trabalhados solos compactados, cuja característica básica é o baixo índice de vazios (relação entre volume de vazios e volume de sólidos), utilizou-se um permeâmetro de carga variável, instrumento mais recomendado para este tipo de ensaio. Assim, os corpos de prova do ensaio de permeabilidade puderam ser montados na condição de máxima eficiência da compactação, ou seja, $\omega_{\text {ótima }}$ e $\rho_{\text {dMáxima }}$ obtidas da curva de compactação.

Os valores dos coeficientes de permeabilidade ( $k$ ) obtidos dos ensaios de laboratório, realizados para o solo, lodo e traços estão descritos na Tabela 5.

Tabela 5 - Coeficientes de permeabilidade

\begin{tabular}{|l|l|}
\multicolumn{1}{|c|}{ Tipo de solo } & \multicolumn{1}{c|}{$k\left(\mathbf{m}^{\left.-s^{-1}\right)}\right.$} \\
\hline Solo Argiloso & $1,0 \times 10^{-9}$ \\
\hline Traço argiloso 1:0,5 & $6,3 \times 10^{-10}$ \\
\hline Traço argiloso 1:1 & $3,1 \times 10^{-10}$ \\
\hline Solo Arenoso & $3,5 \times 10^{-9}$ \\
\hline Traço Arenoso 1:0,25 & $5,2 \times 10^{-9}$ \\
\hline
\end{tabular}

Observa-se que todos os materiais apresentaram $\mathrm{k}$ na faixa de $10^{-10}$ e $10^{-9} \mathrm{~m} \cdot \mathrm{s}^{-1}$, mostrando uma variação de até dez vezes. Ressalta-se ainda que tais 
valores enquadram-se nos valores referência para materiais de baixa permeabilidade, indicados para uso em obras de aterro sanitário (BOSCOV, 2008). Vale destacar que a granulometria pedregulhosa do lodo não alterou significativamente a permeabilidade dos solos aos quais foi acrescido, uma vez que esta foi perceptivelmente reduzida durante o processo de compactação - observou-se a quebra dos torrões do lodo quando compactado.

\section{CONCLUSÃO}

O incremento de lodo de ETA aos solos estudados, após compactação, mostrou-se viável, uma vez que os coeficientes de permeabilidade apresentaram valores menores para os traços com o solo argiloso e próximo para o traço com o solo arenoso quando comparados aos solos compactados sem adição do lodo. Isso evidencia o potencial das misturas na retenção de percolados dos aterros e ratifica a indicação da aplicação do lodo ao solo para a confecção das barreiras impermeabilizantes. Além disso, a codisposição do lodo em si apresenta-se como um ganho para o gerenciamento deste resíduo, visto que, uma vez observada sua potencialidade, ETA's de pequeno porte podem vir a utilizar de tal técnica, minimizando volume de um resíduo que poderia ser destinado ao aterro sanitário, bem como a eventual necessidade de implantação de tecnologias mais onerosas.

\section{AGRADECIMENTO}

Agradecemos a SANEPAR pelo apoio financeiro concedido à pesquisa.

\section{REFERÊNCIAS}

ABNT - Associação Brasileira de Normas Técnicas. NBR 7181 Análise Granulométrica. Rio de Janeiro: ABNT, 1984.

. NBR 6508 - Determinação da Massa Específica dos Grãos. Rio de Janeiro: ABNT, 1984.

. NBR 6459 - Determinação do Limite de Liquidez. Rio de Janeiro: ABNT, 1984.

. NBR 7180 - Determinação do Limite de Plasticidade. Rio de Janeiro: ABNT, 1984.
NBR 6457 - Amostras de solo: preparação para ensaios de compactação e ensaios de caracterização. Rio de Janeiro: ABNT, 1986.

NBR 7182 - Solo: Ensaio de Compactação. Rio de Janeiro: ABNT, 1986.

NBR 14545 - Solo: Determinação do coeficiente de permeabilidade de solos argilosos a carga variável. Rio de Janeiro: ABNT, 2000.

ABNT - Associação Brasileira de Normas Técnicas. NBR 10004: Resíduos Sólidos - Classificação. Rio de Janeiro: ABNT, 2004.

BELINCANTA, A.; GUTIERREZ, N.H.M. Compactação de solos. Maringá: EDUEM, 2010. 76p.

BERALDO, F. M, TEIXEIRA, R. S., RODRIGUEZ, T. T. Caracterização física, capacidade de compactação e permeabilidade de lodo de ETA. In: XX ENCONTRO ANUAL DE INICIAÇÃO CIENTÍFICA - UEPG, 2011. Anais... CD ROM ANAIS DO XX EAIC 2011. Ponta Grossa: UEPG, 2011. p. 4.

BOSCOV, M. E.G. Geotecnia Ambiental. São Paulo: Oficina de textos, 2008. 248p.

FRANCESCHET, M.; CASTILHOS JUNIOR, A. B.; MACCARINI, M.; PRIM, E. C. C.; FUNARI, C. Estudodos solos utilizados para a impermeabilização da camada de base e de cobertura de aterros sanitários de Santa Catarina. In: Congresso Brasileiro de Engenharia Sanitária e Ambiental, 23, Campo Grande: Anais... Campo Grande: [s.n.], 2005.

HAMADA, J.; CALCAS, D.A.N.Q.P.; GIACHETI, H.L. Influência da compactação de um solo arenoso na infiltração e retenção de carga orgânica de chorume. Eng. Sanit. Ambient. [s.l]:[s.n], 2004. vol.9, n.3, p. 180-186.

HAULY, S.L. Parâmetros de comportamento do solo compactado da cidade de Londrina. 2010. 110 fls. Trabalho de Conclusão de Curso (Graduação em Engenharia Civil) - Universidade Estadual de Londrina, Londrina/PR. 2010.

IPEA, Instituto de Pesquisa Econômica Aplicada. Diagnóstico dos Resíduos Sólidos Urbanos: Relatório de Pesquisa. MILANEZ et al. [coord.]. Brasília: IPEA, 2012.

KATAYAMA, V.T. Quantificação da produção de lodos de estação de tratamento de água de ciclos completo: uma análise crítica. 2012. 144 f. Dissertação (Mestrado em Engenharia - Engenharia Hidráulica) - Escola Politécnica, Universidade de São Paulo. São Paulo: USP, 2012.

LANGE, L.C.; AMARAL, M.C.S. Geração e características do lixiviado. In: Estudos de Caracterização e Tratabilidade de Lixiviados de Aterros Sanitários para as Condições Brasileiras. Luciana Paulo Gomes (coordenadora). Rio de Janeiro: ABES, 2009. 360p.

OLIVEIRA JUNIOR, O. M., FERNANDES, F., RODRIGUEZ, T. T. Caracterização Física de Lodo de Estação de Tratamento de Água Retirado de Leito de Secagem. XIX Encontro Anual de Iniciação Cientí- 
fica, EAIC 2010. UNICENTRO, Guarapuava: UNICENTRO, 2010. 4p. CD-ROM.

PAIVA NETO, J. E. de; et al. Observações gerais sobre os grandes tipos de solo do estado de São Paulo. Bragantia [on-line]. 1951, vol.11, n.7-9, pp. 227-253. Disponível em: <http://www.scielo.br/ pdf/brag/v11n7-9/05.pdf> Acesso em: 13 set. 2014.

PEREIRA, V.E. Disposição de lodo adensado de ETA em ETE com tratamento primário quimicamente assistido. 2011. 170 f. Dissertação (Pós-graduação da Faculdade de Engenharia Civil, Arquitetura e Urbanismo) - Universidade Estadual de Campinas. Campinas: UNICAMP, 2011.

PIERANGELI, M. A. P.; GUILHERME, L. R.G.; OLIVEIRA, L. R.; CURI, N.; SILVA, M. L. N. Efeito da força iônica da solução de equilíbrio sobre a adsorção/desorção de chumbo em latossolos brasileiros. Pesquisa Agropecuária Brasileira, v.36, n.8, p.1077-1084. 2001.

ROCHA, G. C.; BARROS, O. N. F.; GUIMARÃES, M. F. Distribuição espacial e características dos solos do Campus da Universidade Estadual de Londrina, PR. Londrina: Ciências Agrárias, 1991, Vol.12, n.1, p. 21-25.
RODRIGUEZ, T. T. et al. Estudo da Compactação de Lodo de ETA para Uso em Aterros Sanitários. In: REGEO/Geossintéticos 2011, 2011, Belo Horizonte. REGEO/Geossintéticos 2011. São Paulo: ABMS, 2011.v. 1. p. 1-8.

SANTOS, J.A. Compactação: elementos teóricos. Instituto Superior Técnico, Departamento de Engenharia Civil e Arquitetura - Mestrado em Engenharia Civil. 2008.

SILVA, R. C., SILVA, S.M.C.P., TEIXEIRA, R.S. Caracterização geotécnica do lodo da Estação de Tratamento de Água Cafezal (Londrina-Paraná). In: Anais do XXXI Congresso Interamericano AIDIS. Santiago: 2008. Vol.1, 1-9.

SILVEIRA, C. Desaguamento de Lodo de Estações de Tratamento de Água por Leito de Drenagem / Secagem com Manta Geotêxtil. 2012. 136 f. Dissertação (Pós-Graduação em Engenharia de Edificações e Saneamento). Londrina: UNEL, 2012.

TEIXEIRA, R.S.; RODRIGUEZ, T.T.; FERNANDES, F. Uso do Lodo de ETA em Aterro Sanitário. Lodo de Estações de Tratamento de Água - Gestão e Perspectivas Tecnológicas. 1ed. Curitiba: Sanepar, 2013.v. 1, p. 410-440. 